\title{
The analysis of a precast sheer wall building
}

\author{
Qi Hu ${ }^{1, a *}$, Geng Jiao ${ }^{1, b}$, Liu Kang ${ }^{1, c}$ \\ ${ }^{1}$ Beijing Shunyi District Linhe Street No. 15, China \\ aqihu_810@163.com, b'gengjiao @cscec.com, aliukang @cscec.com,
}

Keywords: Precast shear wall structure, YJK-EP, Anti-seismic performance, Elastic-plastic analysis.

Abstract. In this paper a 33 story precast shear wall structure is analyzed. In order to study the safety of the tall parapet wall the parapet wall is established in the model. Structure analysis software YJK-EP is taken for the elastic-plastic analysis of this precast sheer wall structure, specifically, the whole anti-seismic performance under rare earthquake is analyzed, three seismic waves, one artificial wave and two natural waves, are loaded according to code[1], and their reaction under earthquake in the direction of $\mathrm{X}$ and $\mathrm{Y}$ are calculated. The result of the analysis shows that the inter layer displacement angel under rare earthquake is much smaller than the norm limits (1/100)[2], which indicates that the structure can meet the requirement of the code in terms of overall anti-seismic performance. Damage image of the shear wall shows that the parapet damage is minor and the parapet is in elastic stage.

\section{Introduction}

In recent years, with the rapid development of computer technology, software and the finite element technology, nonlinear analysis methods of structures have got breakthrough progress ${ }^{[3]}$. Many scholars have carried out the elastic-plastic analysis of many complex structures ${ }^{[4-6]}$. This paper a precast sheer wall building is analyzed by YJK. The selected prefabricated building, 33 floors in total, $2.9 \mathrm{~m}$ high for each floor and $3.7 \mathrm{~m}$ high for basement, is whole prefabricated above cast-in-place ground except the basement. In order to study the whole anti-seismic performance of the structure and the anti-seismic performance impact of the height of strengthened floor onto the 33 floors building under big earthquake, the elastic-plastic response of the structure is analyzed. According to the code, three waves, one artificial wave and two natural waves, are selected and studied for the seismic response in main direction $\mathrm{X}$ and $\mathrm{Y}$ separately, the responses of the 33 floors building structure under the three waves of earthquake are studied and compared.

\section{The structure model}

The elastic-plastic analysis is taken for the 33 floors building, which is of 95.7m height of main body structure, YJK elastic-plastic calculation model (YJK-EP for short) is chosen as Fig.1..

Considering of the complex elastic-plastic analysis theory and practical reinforcement of the structure, the elastic-plastic model can be simplified properly in order to get steady and reliable result. Also, to make sure that YJK elastic-plastic analysis is unanimous with the designed model and YJK-EP model, the three models should be compared in terms of their overall computing. The result of the overall computing and the first three cycles comparison of the models are shown as table 1, from which the overall index fits well, however, because of the difference among each unit and impact of reinforcement, the calculation result maybe not identical.

Table 1 Comparison of the calculation models

\begin{tabular}{lccc}
\hline & & & \\
& & & \\
& & 19006 & 18817 \\
mass(t) & & 3.52 & 3.33 \\
\multirow{2}{*}{ period (s) } & T2 & 2.98 & 2.72 \\
& T3 & 2.05 & 1.92 \\
\hline
\end{tabular}




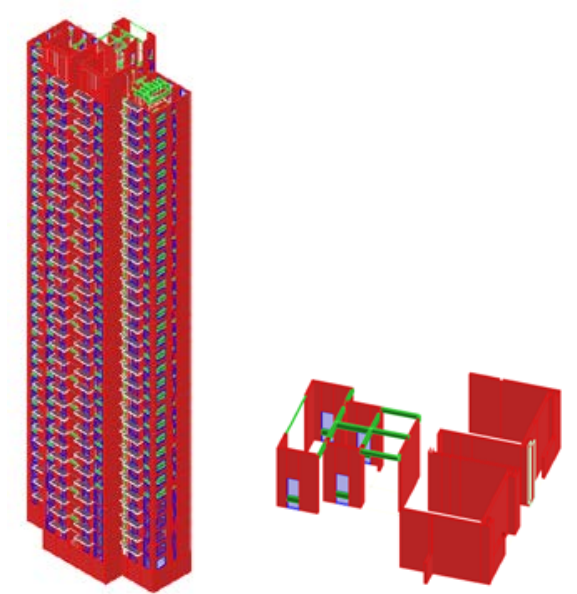

Fig.1 YJK model of 33 floors structure

\section{Earthquake waves}

During the nonlinear time-history analysis, three earthquake waves are selected by YJK, one artificial wave and two natural waves, the main direction oscillogram and response spectrum are seen in Fig.2 and Fig.3.

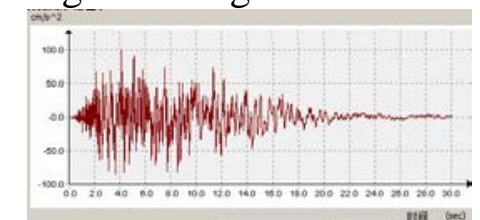

ArtWave-RH3TG035



Chi-Chi, Taiwan-05_NO_2982

Fig.2 Earthquake wave

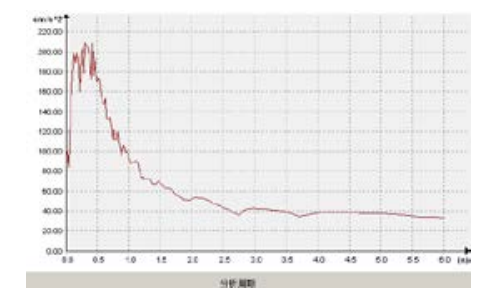

ArtWave-RH3TG035

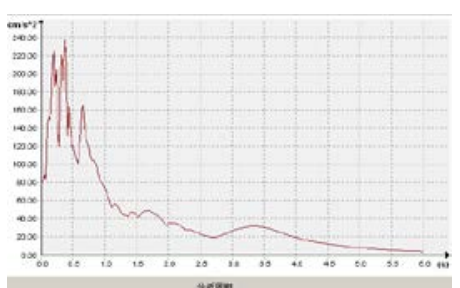

Chi-Chi, Taiwan-05_NO_2982

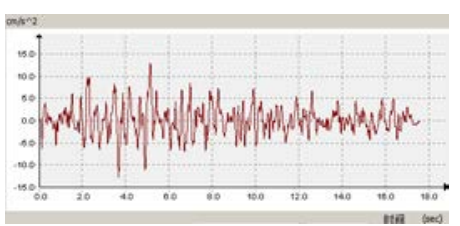

Manjil, Iran_NO_1639

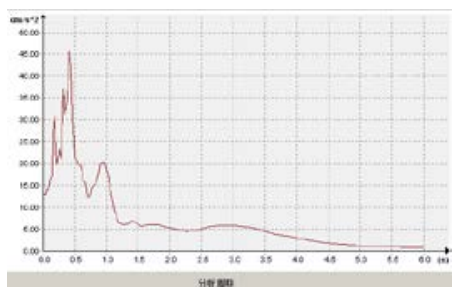

Manjil, Iran_NO_1639

Fig.3 Spectrum of the earthquake wave

Table 2 comparison between earthquake wave base shear force and mode decomposition response spectrum base shear force

\begin{tabular}{ccc}
\hline & $\begin{array}{c}\text { Shear force X } \\
\text { direction } \\
(\mathrm{KN})\end{array}$ & $\begin{array}{c}\text { Shear force } \\
\text { Y direction } \\
(\mathrm{KN})\end{array}$ \\
\hline Spectrum & 16356 & 16444 \\
ArtWave & 12797 & 13386 \\
N.Palm & 12145 & 13816 \\
Manjil & 15442 & 14536 \\
Average & 13462 & 13913 \\
\hline
\end{tabular}

From table 3, the minimum base sheer of $\mathrm{X}$ direction by earthquake waves time-history analysis is $12145 \mathrm{kN}$, greater than the $65 \%$ of the response spectrum base sheer $16356 \mathrm{KN}$, the average of the base sheer from the three earthquake waves time-history analysis is $13462 \mathrm{kN}$, which is greater than the $80 \%$ of response spectrum. The results of base sheer in Y direction also satisfy the above two condition. The selected earthquake waves for time-history analysis meet the requirement of the code 
for seismic design of building[1]. Based on the feature of plane and façade of the structure, earthquake waves are input in orthogonal direction in plane and vertically, and the peek acceleration ratio in primary and secondary direction is 1:0.85:0.65, for which $\mathrm{V}$ direction and $\mathrm{Y}$ direction are calculated as primary direction, the peek acceleration in primary direction is taken as 220gal.

\section{Calculation results}

Under the load of three waves, the maximum inter story drift angle of the structure by YJK-EP are compared as Table 3-4.

Table 3 displacement angle of $\mathrm{X}$ direction

\begin{tabular}{|c|c|c|c|c|}
\hline Floor & RH3TG & Chi-Chi & Manjil & Average \\
\hline 1 & $1 / 1271$ & $1 / 1267$ & 1/1379 & $1 / 1304$ \\
\hline 2 & $1 / 740$ & $1 / 651$ & $1 / 708$ & $1 / 698$ \\
\hline 3 & $1 / 558$ & $1 / 495$ & $1 / 556$ & $1 / 535$ \\
\hline 4 & $1 / 499$ & $1 / 435$ & $1 / 473$ & $1 / 467$ \\
\hline 5 & $1 / 468$ & $1 / 420$ & $1 / 443$ & $1 / 443$ \\
\hline 6 & $1 / 444$ & $1 / 409$ & $1 / 407$ & $1 / 419$ \\
\hline 7 & $1 / 432$ & $1 / 397$ & $1 / 403$ & $1 / 410$ \\
\hline 8 & $1 / 437$ & $1 / 384$ & $1 / 388$ & $1 / 402$ \\
\hline 9 & $1 / 419$ & $1 / 376$ & $1 / 374$ & $1 / 388$ \\
\hline 10 & $1 / 409$ & $1 / 372$ & $1 / 352$ & $1 / 376$ \\
\hline 11 & $1 / 395$ & $1 / 368$ & $1 / 343$ & $1 / 367$ \\
\hline 12 & $1 / 389$ & $1 / 362$ & 1/333 & $1 / 360$ \\
\hline 13 & $1 / 381$ & $1 / 358$ & $1 / 315$ & $1 / 349$ \\
\hline 14 & $1 / 365$ & $1 / 353$ & $1 / 320$ & $1 / 345$ \\
\hline 15 & $1 / 358$ & $1 / 359$ & $1 / 302$ & $1 / 338$ \\
\hline 16 & $1 / 351$ & $1 / 354$ & $1 / 294$ & $1 / 331$ \\
\hline 17 & $1 / 351$ & $1 / 358$ & $1 / 286$ & $1 / 329$ \\
\hline 18 & $1 / 352$ & $1 / 364$ & $1 / 282$ & $1 / 328$ \\
\hline 19 & $1 / 353$ & $1 / 369$ & $1 / 280$ & $1 / 329$ \\
\hline 20 & $1 / 352$ & $1 / 370$ & $1 / 286$ & $1 / 332$ \\
\hline 21 & $1 / 355$ & $1 / 365$ & $1 / 274$ & $1 / 326$ \\
\hline 22 & $1 / 361$ & $1 / 374$ & $1 / 272$ & $1 / 329$ \\
\hline 23 & $1 / 372$ & $1 / 383$ & $1 / 271$ & $1 / 334$ \\
\hline 24 & $1 / 380$ & $1 / 396$ & $1 / 270$ & $1 / 339$ \\
\hline 25 & $1 / 392$ & $1 / 392$ & $1 / 274$ & $1 / 343$ \\
\hline 26 & $1 / 394$ & $1 / 405$ & $1 / 288$ & $1 / 354$ \\
\hline 27 & $1 / 410$ & $1 / 417$ & $1 / 287$ & $1 / 361$ \\
\hline 28 & $1 / 424$ & $1 / 437$ & $1 / 287$ & $1 / 369$ \\
\hline 29 & $1 / 435$ & $1 / 448$ & $1 / 296$ & $1 / 379$ \\
\hline 30 & $1 / 457$ & $1 / 465$ & $1 / 317$ & $1 / 401$ \\
\hline 31 & $1 / 478$ & $1 / 487$ & $1 / 322$ & $1 / 414$ \\
\hline 32 & $1 / 464$ & $1 / 516$ & $1 / 326$ & $1 / 419$ \\
\hline 33 & $1 / 329$ & $1 / 572$ & $1 / 229$ & $1 / 328$ \\
\hline 34 & $1 / 829$ & $1 / 1328$ & $1 / 434$ & $1 / 704$ \\
\hline
\end{tabular}


Table 4 displacement angle of Y direction

\begin{tabular}{|c|c|c|c|c|}
\hline Floor & RH3TG & Chi-Chi & Manjil & Average \\
\hline 1 & $1 / 1318$ & $1 / 2833$ & $1 / 2174$ & $1 / 1908$ \\
\hline 2 & $1 / 621$ & $1 / 1497$ & $1 / 966$ & $1 / 906$ \\
\hline 3 & $1 / 457$ & 1/1099 & $1 / 720$ & $1 / 668$ \\
\hline 4 & 1/372 & $1 / 929$ & $1 / 577$ & $1 / 546$ \\
\hline 5 & $1 / 328$ & $1 / 839$ & $1 / 513$ & $1 / 484$ \\
\hline 6 & $1 / 293$ & $1 / 767$ & $1 / 452$ & $1 / 433$ \\
\hline 7 & $1 / 266$ & $1 / 714$ & $1 / 411$ & $1 / 395$ \\
\hline 8 & $1 / 243$ & $1 / 664$ & $1 / 380$ & $1 / 363$ \\
\hline 9 & $1 / 227$ & $1 / 625$ & $1 / 353$ & $1 / 340$ \\
\hline 10 & $1 / 218$ & $1 / 596$ & $1 / 327$ & $1 / 322$ \\
\hline 11 & $1 / 208$ & $1 / 570$ & $1 / 309$ & $1 / 306$ \\
\hline 12 & $1 / 197$ & $1 / 548$ & $1 / 289$ & $1 / 290$ \\
\hline 13 & $1 / 192$ & $1 / 532$ & $1 / 279$ & $1 / 281$ \\
\hline 14 & $1 / 184$ & $1 / 517$ & $1 / 269$ & $1 / 271$ \\
\hline 15 & $1 / 182$ & $1 / 509$ & $1 / 260$ & $1 / 265$ \\
\hline 16 & $1 / 178$ & $1 / 501$ & $1 / 255$ & $1 / 260$ \\
\hline 17 & $1 / 178$ & $1 / 500$ & $1 / 248$ & $1 / 257$ \\
\hline 18 & $1 / 175$ & $1 / 495$ & $1 / 243$ & $1 / 253$ \\
\hline 19 & $1 / 175$ & $1 / 495$ & $1 / 239$ & $1 / 252$ \\
\hline 20 & $1 / 169$ & $1 / 490$ & $1 / 229$ & $1 / 243$ \\
\hline 21 & $1 / 173$ & $1 / 487$ & $1 / 231$ & $1 / 246$ \\
\hline 22 & $1 / 175$ & $1 / 482$ & $1 / 227$ & $1 / 246$ \\
\hline 23 & $1 / 177$ & $1 / 476$ & $1 / 222$ & $1 / 244$ \\
\hline 24 & $1 / 177$ & $1 / 468$ & $1 / 221$ & $1 / 244$ \\
\hline 25 & $1 / 181$ & $1 / 465$ & $1 / 223$ & $1 / 247$ \\
\hline 26 & $1 / 177$ & $1 / 461$ & $1 / 228$ & $1 / 246$ \\
\hline 27 & $1 / 182$ & $1 / 461$ & $1 / 230$ & $1 / 250$ \\
\hline 28 & $1 / 185$ & $1 / 468$ & $1 / 230$ & $1 / 252$ \\
\hline 29 & $1 / 189$ & $1 / 469$ & $1 / 228$ & $1 / 254$ \\
\hline 30 & $1 / 183$ & $1 / 471$ & $1 / 235$ & $1 / 253$ \\
\hline 31 & $1 / 191$ & $1 / 477$ & $1 / 241$ & $1 / 261$ \\
\hline 32 & $1 / 193$ & $1 / 483$ & $1 / 241$ & $1 / 263$ \\
\hline 33 & $1 / 198$ & $1 / 491$ & $1 / 233$ & $1 / 264$ \\
\hline 34 & $1 / 550$ & $1 / 1340$ & $1 / 644$ & $1 / 729$ \\
\hline
\end{tabular}

The maximum layer displacement angle by RH3TG in Y direction is the greatest, the structure damage picture under RH3TG is shown as Fig.5, from which the structure damage is focus on the structure coupling beam, the sheer wall is little damaged, of which the damage is mainly focus on lower part, and decreasing as the floor rises.
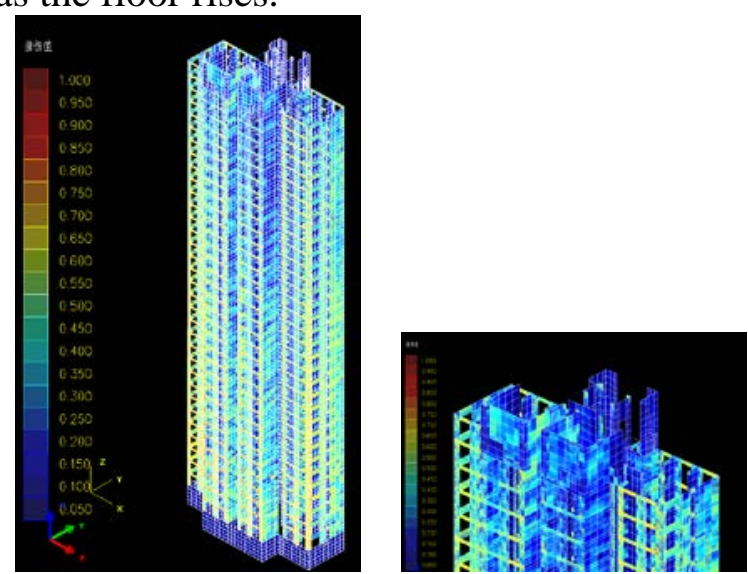

Fig.5 Structure damage 


\section{Conclusions}

The maximum inter layer displacement angel by elastic-plastic analysis is much smaller than the code limits (1/100) [2], which indicates that the structure meet the requirement of the code in terms of overall anti-seismic performance. The structure damage picture shows that the structure damage is focus on the structure coupling beam, the overall of the sheer wall is little damaged, with damage mainly focus on lower part, and decreasing as the floor rises. Damage image of the parapet shows that the parapet damage is minor and the parapet is in elastic stage under rare earthquake.

\section{References}

[1]GB50011-2010, 2010. Code for seismic design of buildings. Beijing: China Architecture \& Building. Press.

[2]JGJ3-2010, 2010. Technical Specification for Concrete Structures of Tall Building. Beijing: China Architecture \& Building. Press.

[3]Zhou Xingwei, Li Zhishan, Li Yungui. development and application of concrete hysteretic uniaxial constitutive model Based on ABAQUS fiber beam element[A]; 14th sessionof the National Conference on Engineering of Computer Applications Proceedings,2008.

[4]Qi, Hu; Li, Yun-Gui; Lu, Xilin, Dynamic Nonlinear Analysis of The Shanghai Pudong Shangrila Hotel Extension Engineering, Applied Mechanics and Materials,2013,v 438-439, pp 1510-1513.

[5]Sivashinsky G I. Nonlinear analysis of hydrodynamic instability in laminar flames-I. Derivation of basic equations[J]. Acta Astronautica, 1977, 4(77):1177-1206.

[6]Fajfar P. A nonlinear analysis method for performance-based seismic design[J]. Earthquake Spectra, 2000, 16(3):573-592. 